УДК 621.3

Є.C. Карплюк ${ }^{1}$, канд.техн.наук, А.А. Макаренкова ${ }^{2}$, канд.фіз.-мат.наук.,

А.П. Макаренков ${ }^{2}$, канд.фріз.-мат.наук, Г.С. Порєва ${ }^{1}$

${ }^{1}$ Національний технічний університет України «Київський політехнічний інститут»,

вул. Політехнічна, 16, корпус 12, м. Київ, 03056, Україна.

${ }^{2}$ Інститут Гідромеханіки НАН України, каб. 711, вул. Желябова 8/4, 03680, Київ, Україна.

\title{
Виявлення характерних акустичних ознак пацієнтів з ХОЗЛ на основі біспектрального аналізу звуків дихання
}

Мета даних досліджень - виявлення найбільш інформативних характеристик звуків дихання, що визначають аускультативні, діагностичні ознаки у хворих хронічним обструктивним захворюванням легенів (ХОЗЛ) на основі поліспектрального аналізу. Була розроблена методика ітераційного поліспектрального аналізу звуків дихання на основі розрахунку непараметричного біспектру (за допомогою прямого і непрямого методів обчислення) і параметричного біспектру. Запропоновані графрічні та чисельні показники, що об'єктивізують характерні діагностичні ознаки ХОЗЛ. Розроблений метод може служити допоміжним засобом для лікарів при ідентифікації ХОЗЛ у пацієнтів. Бібл. 6, рис. 4, табл. 2.

Ключові слова: електронна аускультація, ХОЗЛ, легеневі звуки, біспектр, параметричний біспектр.

\section{Вступ}

Використання сучасних діагностичних методів у практичній медицині, що дозволяють отримувати більш точні дані про стан органів та систем організму людини, значно розширюють можливості лікарів вибирати оптимальні методи лікування. В останні роки все більш широке застосування в медицині знаходять високоінформатівні методи обстеження організму людини, в тому числі, і електронна аускультація (реєстрація, комп'ютерна обробка і візуалізація звуків дихання), яка дозволяє виявляти і об'єктивізувати характерні діагностичні ознаки захворювань бронхолегеневої системи.

Хронічне обструктивне захворювання легенів (ХОЗЛ) відноситься до професійних хвороб людини, що часто зустрічаються. Нині відзначається тенденція до збільшення поширеності ХОЗЛ. За даними Всесвітньої Організації Охорони здоров'я за період з 2000 по 2011 ХОЗЛ посідає четверте місце в таблиці причин смертності в усьому світі [4].

Глобальна ініціатива з хронічного обструктивного захворювання легенів - спільний проект Інстута серця, легенів і крові (США) та ВООЗ визначають ХОЗЛ як "захворювання, що характеризується частково незворотнім обмеженням повітряного потоку. Обмеження повітряного потоку, як правило, має неухильно прогресуючий характер і викликане аномальною запальною реакцією легеневої тканини на подразнення різними патогенними частками і газами".

Поява нових екологічно безпечних неінвазивних методів виявлення характерних аускультативних діагностичних ознак ХОЗЛ на ранніх стадіях їх розвитку ініціювала авторів зробити оцінку інфрормативності методу комп'ютерної обробки звуків дихання на основі поліспектрального аналізу.

Комп'ютерна реєстрація і подальша обробка звукової інформації, що знімається 3 поверхні грудної клітини пацієнтів, проводилася за допомогою чотириканального фоноспірографіческого комплексу «КоРА-03М», розробленого в Інституті гідромеханіки НАН України. Комплекс сертифікований в УКРТЕСТМЕТРСТАНДАРТЕ України і дозволений МОЗ для застосування в медичних установах країни [6].

Було обстежено 134 пацієнтів, з них: 59 людина - шахтарі, хворі на ХОЗЛ (II стадія в фразі загострення або згасаючого загострення), 38 практично здорових осіб, 37 пацієнтів контрольної групи, яку склали шахтарі без патології органів дихання. Діагнози у пацієнтів були попередньо верифіковані стандартними клінічними методами функціональної діагностики, включаючи рентгенографію, спірометрію, бодіплетізмографію, визначення дифузійної здатності альвеолокапілярної мембрани, загальноклінічні дослідження.

(с) Карплюк Є.С., Макаренкова А.А.,. Макаренков А.П., Порєва Г.С., 2014 


\section{Результати дослідження}

У попередніх роботах авторів розглядалося обгрунтування застосування поліспектрального аналізу до аналізу звуків легенів і ефективність такого підходу [2,3,5].

У даних дослідженнях взяті за основу методики, що запропоновані в [3], для аналізу звуків дихання хворих на ХОЗЛ. Однак у попередніх роботах проводилася диференціація окремих підкласів звуків, таких, як дрібнопузирчасті хрипи та тріски. Виявлення характерних ознак певного захворювання більш широка і складна задача, тому вказаний метод вимагав деяких уточнень і доповнень, що і було зроблено в ході даних досліджень.

Таким чином аналіз зареєстрованих звуків дихання проводився на основі непараметричного розрахунку біспектра (прямий і непрямий метод) і параметричного розрахунку.

Звуки дихання у пацієнтів реєструвалися комплексом синхронно в 4 точках: канал 1 і канал 4 ліворуч і праворуч на рівні 2-го ребра по среднеподключічной лінії, канал 2 і канал 3 справа і зліва на рівні 7-х ребер під кутом лопатки. Точки фріксації датчиків вибиралися відповідно до рекомендацій пульмонологів.

Зареєстровані сигнали перш ніж відправлятися на модуль аналізу, проходили обов'язковий етап попередньої обробки. Суть адаптивної обробки полягав у виключенні з сигналу можливих випадкових перешкод, пов'язаних із зовнішніми перешкодами.

Далі починався етап аналізу. Насамперед розраховувався біспектр за прямим методом [3,1]. На основі отриманого тривимірного біспектру були побудовані графіки діагонального зрізу цих біспектрів. У здорових пацієнтів сигнали у всіх чотирьох каналах мали однотипний вид діагонального зрізу - з доволі пологими вершинами (плавно спадають від максимуму до мінімуму) в симетричних областях (рис.1). У хворих на ХОЗЛ вершини максимуму значно загострені (рис.2). Крім того, видно, що у хворих на ХОЗЛ має місце наявність вторинних вершин, що володіють сумірною 3 максимальною амплітудою (рис 4, канали 2 і 3).

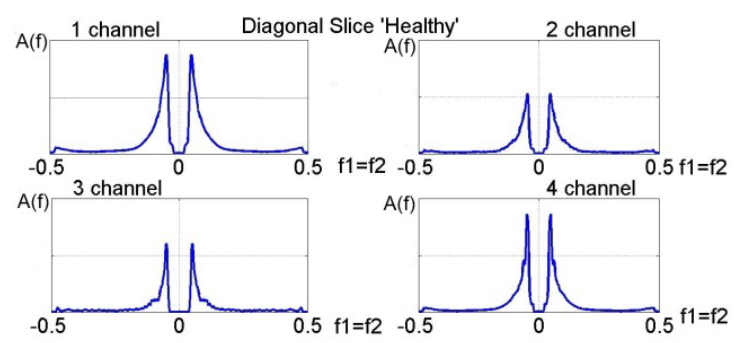

Рис. 1. Графічне зображення діагонального зрізу біспектру здорового пацієнта

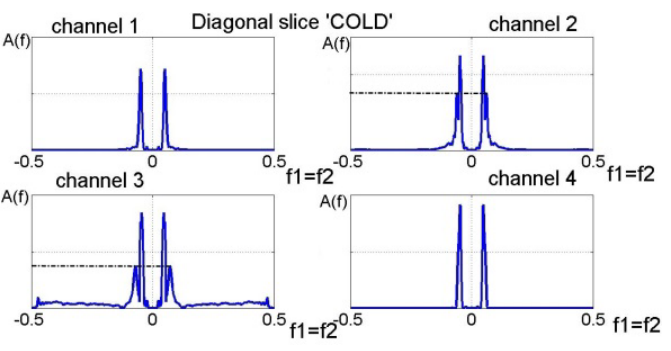

Рис. 2. Графічне зображення діагонального зрізу пацієнта $з$ ХОЗЛ

Діагональні зрізи біспектра були проаналізовані на предмет знаходження п'яти максимальних вершин кожного біспектра i бічастот, відповідним цим вершинам. В результаті були знайдені певні закономірності, що дозволяють диференціювати групи здорових людей і пацієнтів з ХОЗЛ. У здорових людей були виявлені два типи «бічастотних патернів». Найбільш часто зустрічаються рівномірно (практично лінійно) зростаючі бічастоти для кожної наступної вершини (по мірі зменшення амплітуди). Менш часто зустрічаються, але також свідчить про відсутність акустичних ознак захворювання ХОЗЛ - це рівномірно зростаючі чотири бічастоти і різкий спад для п'ятої частоти. У табл. 1 наведені значення п'яти зазначених бічастот $f i,(i=1 \ldots 5)$ для чотирьох каналів, на яких проводилася реєстрація сигналів, ці значення у вказаній послідовності і $€$ «бічастотними патернами».

Таблиця 1. Значення п'яти бічастот для 4 реєстрованих каналів, отримані при прямому методі розрахунку біспектру здорової людини

\begin{tabular}{|c|l|l|l|l|}
\hline$f$ & \multicolumn{1}{|c|}{1} & \multicolumn{1}{c|}{3} & \multicolumn{1}{c|}{3} \\
\hline$f 1$ & 0,047 & 0,047 & 0,051 & 0,045 \\
\hline$f 2$ & 0,066 & 0,061 & 0,065 & 0,061 \\
\hline$f 3$ & 0,109 & 0,078 & 0,090 & 0,078 \\
\hline$f 4$ & 0,131 & 0,090 & 0,107 & 0,092 \\
\hline$f 5$ & 0,029 & 0,107 & 0,133 & 0,121 \\
\hline
\end{tabular}


Для пацієнтів з ХОЗЛ було виявлено більшу кількість «бічастотних патернів», що пояснюється різними супутніми акустичними ознаками пацієнтів (табл. 2). У одних - це наявність сухих хрипів, у інших - вологих, у когось присутні і сухі, і вологі, і т.д. Однак, характерні для здорових людей патерни у хворих на ХОЗЛ практично не зустрічається. Якщо ж на якомусь каналі отриманий патерн тотожний зі здоровим, тоді проводиться наступний етап аналізу.

Таблиця 2. Значення п'яти бічастот для 4 реєстрованих каналів, отримані при прямому методі розрахунку біспектру пацієнта з ХОБЛ

\begin{tabular}{|c|c|c|c|c|}
\hline$f$ & \multicolumn{1}{|c|}{1} & 2 & & 3 \\
\hline$f 1$ & 0,051 & 0,049 & 0,049 & 0,047 \\
\hline$f 2$ & 0.025 & 0,061 & 0,068 & 0,023 \\
\hline$f 3$ & 0,067 & 0,072 & 0,088 & 0,035 \\
\hline$f 4$ & 0,082 & 0,084 & 0,023 & 0,078 \\
\hline$f 5$ & 0,104 & 0,031 & 0,147 & 0,098 \\
\hline
\end{tabular}

На цьому етапі також розраховується біспектр, але на основі непрямого методу [1]. Знову отримуємо «біспектральний патерн». Якщо він відрізняється від «здорового», то приймається рішення про наявність характерних ознак захворювання. Якщо ж патерн відповідає «здоровому», то можна сказати, що в даному каналі відсутні характерні для ХОЗЛ акустичні ознаки.

Крім того, всі сигнали були проаналізовані за допомогою параметричного розрахунку біспектра [3,1], який свідчить про наявність фразових зв'язків. У здорових пацієнтів на параметричному біспектрі був виявлений єдиний максимальний пік, отриманий при рівних частотах $f_{1}=f_{2}$, що свідчить про наявність в сигналі квадратично пов'язаних частот $f_{1}=2 f_{1}$. (рис. 3 ). Параметричні біспектри пацієнтів з ХОЗЛ, як правило, мають додаткові вершини квадратично пов'язаних частот (рис. 4). Оцінка параметричного біспектра може служити додатковим допоміжним фрактором для встановлення діагнозу

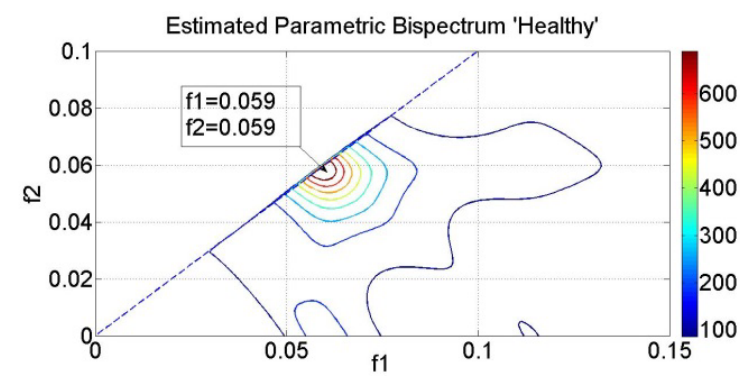

Рис. 3. Контурне зображення параметричного біспектру здорової людини

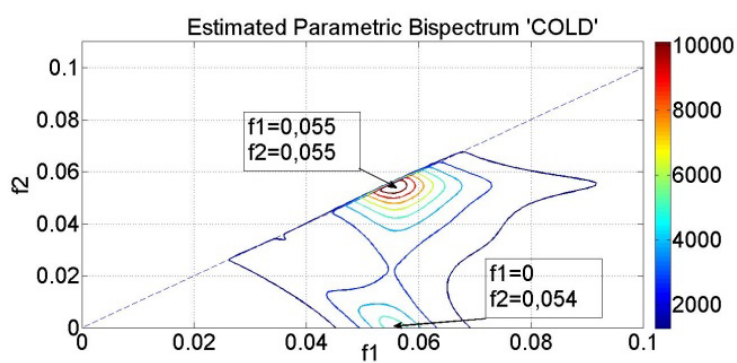

Рис. 4. Контурне зображення параметричного біспектру пацієнта 3 ХОЗЛ

Т.ч., в результаті проведеного біспектрального аналізу у всіх обстежених пацієнтів були підтверджені діагнози, встановлені стандартними клінічними методами функціональної діагностики.

\section{Висновки}

Комп'ютерна діагностика об'єктивізує характерні діагностичні ознаки бронхолегеневих захворювань, у тому числі ХОЗЛ. Запропонований авторами ітераційний метод біспектрального аналізу звуків дихання хворих на ХОЗЛ дозволяе 3 високою ймовірністю ідентифікувати дане захворювання, що може бути хорошим допоміжним інструментом для лікаря. У подальших дослідженнях планується провести ретельний аналіз отриманих «біспектральних патернів» пацієнтів з ХОЗЛ 3 метою диференціації хворих за ступенем і тяжкості захворювання 


\section{Список використаних джерел}

1. Petropulu, A. P. Higher-Order Spectral Analysis. The Biomedical Engineering Handbook: Second Edition. Boca Raton: CRC Press LLC, 2000 - 154 p.

2. Poreva A., Danilov P., Fesechko V. Cumulant Analysis for the Detection of Crackles in Lung Sounds // XXXII International Scientific Conference Electronics and Nanotechnology, 1012 April 2012.: proceedings - Kyiv, 2012. p. 188-189. - ISBN 978-1-4673-4670-2.

3. Poreva, A.; Fesechko, V. Differentiation of moist fine rales and crackles by polyspectral analysis // IEEE XXXIII International Scientific Conference Electronics and Nanotechnology (ELNANO), 16-19 April 2013: proceedings Kyiv, 2013, p.305-309. — ISBN: 978-1-46734670-2
4. http://www.who.int/mediacentre/factsheets/fs30 len/index.html

5. Порєва Г.С. Методика оцінювання легеневих шумів на основі біспектрального аналізу // XII Міжнародна науково-технічна конференція «Фізичні процеси та поля технічних і біологічних об'єктів», 8-10 листопада 2013: матеріали конференції - Кременчуг, 2013 C.114-115. - ISSN: 2305-1353.

6. Свідоцтво про державну реєстрацію “Комплекс фоноспірографрічний комп'ютерний KoPA-03 M1" (№ 5528/2006 р.)

Поступила в редакцию 20 сентября 20142.

УДК 621.3

Е.С. Карплюк ${ }^{1}$, канд.тех.наук, А.А. Макаренкова ${ }^{2}$, канд.фриз.-мат.наук,

А.П. Макаренков ${ }^{2}$, канд.фриз.-мат.наук, А.С. Порева ${ }^{1}$

${ }^{1}$ Национальный технический университет Украины «Киевский политехнический институт», ул. Политехническая, 16, корпус 12, г. Киев, 03056, Украина.

${ }^{2}$ Институт Гидромеханики НАН Украины, каб. 711, ул. Желябова 8/4, 03680, Киев, Украина.

\section{Выявление характерных акустических признаков пациентов с ХОЗЛ на основе биспектрального анализа легочных звуков}

Цель данных исследований - выявление наиболее информативных характеристик звуков дыхания, определяющих аускультативные, диагностические признаки у больных хроническим обструктивным заболеванием легких (ХОЗЛ) на основе полиспектрального анализа . Была разработана методика итерационного полиспектрального анализа звуков дыхания на основе расчета непараметрического биспектра (с помощью прямого и косвенного методов вычисления) и параметрического биспектра. Предложенны графические и численные показатели, которые объективизируют характерные диагностические признаки ХОЗЛ. Разработанный метод может служить вспомогательным средством для пульмонологов при идентифрикации ХОЗЛ у пациентов. Библ. 6, рис. 4, табл. 2.

Ключевые слова: электронная аускультация, ХОЗЛ, легочные звуки, биспектр, параметрический биспектр.

\section{UDC 621.3}

Y. Karplyuk ${ }^{1}$, Ph.D., A. Makarenkova ${ }^{2}$, Ph.D., A. Makarenkov ${ }^{2}$, Ph.D., A. Poreva ${ }^{1}$

${ }^{1}$ National Technical University of Ukraine "Kyiv Polytechnic Institute",

Polytekhnichna Str.,16, Block 12, Off. 413a, 03056, Kyiv, Ukraine.

${ }^{2}$ Institute of Hydromechanics of NAS of Ukraine, Zhelyabova Str. 8/4, Off. 711, 03680, Kyiv, Ukraine.

\section{Specific acoustic features identification based on bispectral analysis of lung sounds of patients with COLD}

The aim of this research is to identify the most informative characteristics of breath sounds that define auscultative, diagnostic features in patients with chronic obstructive lung disease (COLD). The metod 
based on polyspectral analysis. The iterative technique of polyspectral analysis of respiratory sounds was developed and it based on nonparametric bispectrum calculation (using direct and indirect methods of calculation) and parametric bispectrum. Graphical and numerical indicators that objectify typical diagnostic features of COLD was proposed. The method can use as additional tool for physicians in identifying COLD patients. Ref. 6, Fig. 4, Tab. 2.

Keywords: electronic auscultation, COLD, lung sounds, bispectrum, parametric bispectrum.

\section{References}

1. Petropulu, A. P. (2000), "Higher-Order Spectral Analysis. The Biomedical Engineering Handbook": Second Edition. Boca Raton: CRC Press LLC, P. 154.

2. Poreva A., Danilov P., Fesechko V. (2012), "Cumulant Analysis for the Detection of Crackles in Lung Sounds" XXXII International Scientific Conference Electronics and Nanotechnology, 10-12 April 2012.: proceedings. Kyiv, Pp. 188-189

3. Poreva, A.; Fesechko, V. (2013), "Differentiation of moist fine rales and crackles by polyspectral analysis" IEEE XXXIII International Scientific Conference Electronics and Nanotechnology (ELNANO), 1619 April 2013: proceedings. Kyiv, P. 305-3094.

4. http://www.who.int/mediacentre/factsheets/fs310/en/index.html

5. Poreva A. (2013), "Methods of assessment of lung sounds based on bispectrum analysis" XII International scientific and technical conference "Physical processes and fields of technical and biological objects", Conference Proceedings. Kremenchug, Pp.114-115 (Ukr)

6. Certificate of state registration of "Complex phonospirographic computer "KoPA-03M" (№ 5528/2006) (2006) (Ukr) 